\title{
Data Mining for Attitudinal and Belief Profiles Determination towards Hypnosis
}

\author{
María Auxiliadora Franquelo ${ }^{1, *}$, Jose Luis Pastrana-Brincones ${ }^{2}{ }^{\oplus}$, Rafael E. Reigal ${ }^{1}$, Juan P. Morillo-Baro ${ }^{1}{ }^{\circledR}$, \\ Juan A. Vázquez-Diz ${ }^{1}$, Antonio Hernández-Mendo ${ }^{3}{ }^{-1}$ and Verónica Morales-Sánchez ${ }^{3}$ \\ 1 Faculty of Psychology, University of Málaga, 29071 Malaga, Spain; rafareigal@gmail.com (R.E.R.); \\ juanpablo.morillo@gmail.com (J.P.M.-B.); avazquezdiz@gmail.com (J.A.V.-D.) \\ 2 Department of Languages and Computer Science, University of Málaga, 29071 Malaga, Spain; \\ pastrana@lcc.uma.es \\ 3 Department of Social Psychology, Social Work, Anthropology and East Asian Studies, University of Málaga, \\ 29071 Malaga, Spain; mendo@uma.es (A.H.-M.); vomorales@uma.es (V.M.-S.) \\ * Correspondence: auxifranq@uma.es
}

check for

updates

Citation: Franquelo, M.A.;

Pastrana-Brincones, J.L.; Reigal, R.E.;

Morillo-Baro, J.P.; Vázquez-Diz, J.A.;

Hernández-Mendo, A.;

Morales-Sánchez, V. Data Mining for Attitudinal and Belief Profiles

Determination towards Hypnosis.

Sustainability 2021, 13, 7721.

https://doi.org/10.3390/su13147721

Academic Editor: Miltiadis D. Lytras

Received: 18 June 2021

Accepted: 8 July 2021

Published: 10 July 2021

Publisher's Note: MDPI stays neutral with regard to jurisdictional claims in published maps and institutional affiliations.

Copyright: (c) 2021 by the authors. Licensee MDPI, Basel, Switzerland. This article is an open access article distributed under the terms and conditions of the Creative Commons Attribution (CC BY) license (https:/ / creativecommons.org/licenses/by/ $4.0 /)$.

\begin{abstract}
Data mining is a technique that aims to explain large data sets through patterns of behavior, associations, changes, or significant structures in the data. The main goal of this study was to analyze information about beliefs and attitudes towards hypnosis, evaluated by the Valencia Scale of Attitudes and Beliefs Toward Hypnosis, Client version (VSABTH-C) in two temporal moments with a total of 444 participants; developing decision trees in order to discover any sociodemographic factors influencing these variables. The results indicate some influence of gender, education level, and profession on the scores in the scale factors, thus women tended to get higher scores on factors such as Control and Fear; people with a higher educational level tended to get higher scores on factors that denote more positive attitudes and beliefs towards hypnosis; in addition, the psychologist participants showed more positive attitudes and beliefs regarding hypnosis. Considering these results, it would be interesting to carry out similar studies, increasing the size of the sample and also adding some new variables, in order to deepen this relationship and implement changes that would lead people to have more positive attitudes and beliefs regarding hypnosis.
\end{abstract}

Keywords: data mining; hypnosis; beliefs; attitudes

\section{Introduction}

\subsection{Data Mining and Associated Techniques}

Data mining is a technique that attempts to explain large data sets by identifying significant patterns of behavior, associations, changes, or structures in data [1,2]. This allows, through the necessary methodology and technology, the obtaining of useful information from large amounts of data, improving decision-making [3]. Data mining is part of a multidisciplinary area that combines several aspects, such as machine learning, statistics, database technology, modeling, evaluation, and implementation [2]. The techniques used in data mining can be classified as descriptive or predictive, including association, classification, clustering, neural networks, and regression [2,4,5].

Clustering is about assigning data to sets (or clusters) that share certain characteristics [1]. Therefore, elements belonging to a cluster share common properties that also differentiate them from the elements of other clusters [6]. Thus, it is a very useful tool, because it allows the identification of groups in data sets, often not identifiable at first sight $[7,8]$. Furthermore, clustering is often used as a previous step to different algorithms, such as classification or selection of attribute algorithms $[9,10]$.

Classification is the process by which the class model of a problem is developed from a set of labeled data [11]. In addition, the algorithm generates a series of rules used to predict the target variable value from the other variable values [2]. This means that when 
studying a data set, classification rules are extracted and applied to the data in order to predict behavior [12]. In this sense, a classifier determines an instance class $[13,14]$ based on a dataset. WEKA ("Waikato Environment for Knowledge Analysis") software (open source and free access) is an innovative tool used as an API of MATLAB, which contains a multitude of built-in algorithms for data mining and machine learning [2] and implements some classification algorithms. Specifically, the J48 algorithm (a classification tool, extension of the ID3 algorithm, and open source Java implementation of the C4.5 algorithm) has been modified to increase the percentage accuracy of the data mining procedure and has shown significant improvement over the original J48 algorithm [2]. It is used to generate decision trees (or tree-shaped graphical decisions), by creating one acyclic (tree) graph where nodes represent tagged classes and each branch represents a split subset [15]. This tool is often used as a model of a dataset to predict future data behavior [1], which is why it is an important tool in many disciplines and processes [16]. Generally, it involves three steps: (1) selecting an attribute as a target; (2) choosing the attribute that divides the data into the smallest number of subsets (i.e., the best division attribute); and (3) each generated node must return to step 2 (interactive dichotomizer) [1,16].

Quinlan J. R. developed the ID3 algorithm [17], which uses the concept of information gain as a division criterion to perform the division of nodes, with the main or root node acting as the best predictor [1]. The algorithm develops tree classifiers following three steps: (1) the target attribute is selected and its entropy is calculated; (2) the feature with the highest information gain is taken; and (3) a node is created for that feature and steps 1 and 2 are repeated until a completion criterion is obtained [1]. Thus, both this algorithm and the previous one use two main concepts to build trees: entropy and gain of information. Entropy (or measure of data disorder) is a measure that represents the degree of randomness within a data set; therefore, its value will be zero with an homogeneous sample, and will be one when the sample is completely uncertain, i.e., unpredictable $[2,16]$. It is measured in bits, nats, or bans [16]. As shown in Equation (1) and Equation (2), the entropy of any sample $(\vec{y})[2,16]$ is calculated by:

$$
\begin{aligned}
& \operatorname{Entropy}(\vec{y})=-\sum_{j=1}^{n} \frac{\left|y_{i}\right|}{|\vec{y}|} \log \left(\frac{\left|y_{i}\right|}{|\vec{y}|}\right) \\
& \operatorname{Entropy}(j \mid \vec{y})=\left(\frac{\left|y_{i}\right|}{|\vec{y}|}\right) \log \left(\frac{\left|y_{i}\right|}{|\vec{y}|}\right)
\end{aligned}
$$

And as shown in Equation (3), the information gain, defined as the relevance given to an attribute in a data set [2], when the algorithm maximize the gain, by dividing overall entropy because of split argument $\vec{y}$ by $j$, is:

$$
\operatorname{Gain}(\vec{y}, j)=|\operatorname{Entropy}(\vec{y})-\operatorname{Entropy}(j \mid \vec{y})|
$$

Finally, another important aspect in the classification process is pruning, to decrease the classification errors that occur when the tree is generalized, mainly due to the existence of outliers in the data sets $[2,16]$.

\subsection{Attitudes and Beliefs about the Hypnotic Process}

Hypnosis has a large body of scientific evidence in which its effectiveness in improving those programs to which it is attached is evident [18]. However, this effectiveness is modulated by different factors, including the attitudes and beliefs of people who participate in the hypnotic process [19-21]. In terms of clients, their attitudes and beliefs are considered determinants in their hypnotic response [22-24], and showing a positive attitude at the beginning is related to greater progress during treatment $[25,26]$, as well as an improved therapeutic relationship [27]. 
The importance of evaluating those beliefs and attitudes at the beginning of the intervention is derived from the relevance of these aspects to the hypnotic process. The Valencia Scale of Attitudes and Beliefs Toward Hypnosis, Client Version (VSABTH-C) [28] was developed in the context of the Valencia Model of Awakened Hypnosis [29-31] to assess, as suggested by its name, the beliefs and attitudes that clients show towards hypnosis, through eight factors, namely [32,33]: Fear, rating the belief that hypnosis is dangerous; Memory, rating the belief that memories can be affected under hypnosis; Help, rating the belief that hypnosis is an effective technique to complement psychological (or medical) intervention; Control, rating the belief that hypnotized individuals maintain control of their own actions; Collaboration, rating the belief that clients must work closely with therapists in order for the work to be effective; Interest, rating the client's desire to be hypnotized or to be easily hypnotizable; Magic, rating the belief that hypnosis is a magical solution to problems, that it requires no effort at all; and Marginal, rating the belief that hypnosis is something isolated, outside of science.

Taking into account all of these, the main goal of this study was to analyze information related to the beliefs and attitudes of clients towards hypnosis, developing decision trees in order to check if there are sociodemographic factors influencing these variables.

\section{Materials and Methods}

\subsection{Participants}

The sample was composed of a total of 444 participants (fourth-grade students in a psychology bachelor's degree, as well as participants in a university extension course in hypnosis) who responded to the VSABTH-C in 2018 and 2019, ranging in age from 18 to 58 years ( 373 youths, between 18 and 25 years old; 71 adults, between 25 and 58 years old). By gender, the sample was divided into 150 males and 294 females. In terms of educational level, eight participants had achieved a primary education level, 91 participants a middle level, and 345 higher levels. Finally, in terms of profession, 346 were students, 53 psychologists, 4 participants had other health related professions (doctors, nurses, physiotherapists), 5 had sport related professions (trainers), 21 had other professions (not related to health), and 15 were unemployed. All of them responded to the scale with data collections at two time points (time 1 and time 2), with eight months between them, obtaining a total of 888 records. The inclusion criterion was subjects of 18 years old and over. Sample size was determined before any data analysis.

\subsection{Instruments}

The VSABTH-C [28] was used in its online version, formed by eight factors: Fear, Memory, Help, Control, Collaboration, Interest, Magic, and Marginal. In addition, a preliminary questionnaire was included for collecting sociodemographic information about the participants (age, marital status, gender, employment status, studies completed, profession, and information about hypnosis).

The WEKA tool, developed in Java, was used for data mining. This tool allows different data processing and classification options, as well as different file types, ARFF ("Attribute Relation File Format"), CSV ("Comma Separated Values"), C4.5 and binary [1].

\subsection{Procedure}

Participants responded to the scale using the Menpas online psychosocial assessment platform [34,35] between 2018 and 2019. After registering on the platform, participants had to complete a brief sociodemographic data form and then they took the scale. Eight months later, participants had to take the scale again, logging into the platform using their personal identification. The application administrator (one of the authors) gathered and handled this information. Throughout the research process, the ethical principles of the Declaration of Helsinki [36] were followed.

Data were classified in order to obtain relationships between the VSABTH-C factors (Fear, Memory, Help, Control, Collaboration, Interest, Magic, and Marginal) and the 
sociodemographic data collected (age, marital status, gender, employment status, studies completed, profession, and information relating to hypnosis). Relationships were modelled by decision trees using the J48 algorithm.

\subsection{Statistical Analysis}

After pre-processing the data, the data set was used to develop a model using classification algorithms. In our case, the J48 classification algorithm for data processing (extension of the ID3 algorithm) was used to generate decision trees based on the sample. As a model validation method, cross-validation was used to consolidate the independence of the analyses. To carry out these analyses, a set of target variables (one for each tree) and a set of predictors were selected. The program then performed an evaluation, in order to find the best cut-off point and divide the subgroups that will comprise the subjects above and below this division [37]. Once this division was made, the process was repeated as many times as cut-off points could be established by the predictor, and finally the most significant groupings with the least errors were chosen [37]. All measures, manipulations, and exclusions were reported in these studies.

\section{Results}

A total of eight decision trees were developed (one for each factor in the scales at each time point) (Figures 1-8), the socio-demographic variables used were taken as a target to evaluate their influence on the attitudes and beliefs that clients held towards hypnosis at different times.

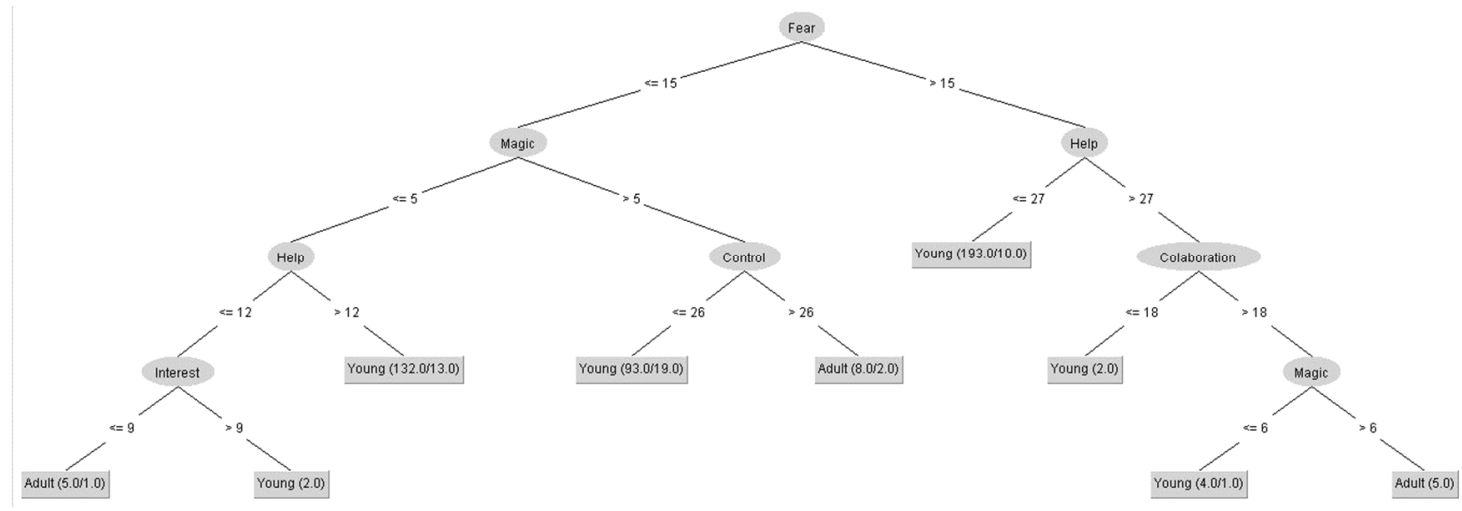

Figure 1. Relationship between scale factors and age of participants at time 1.

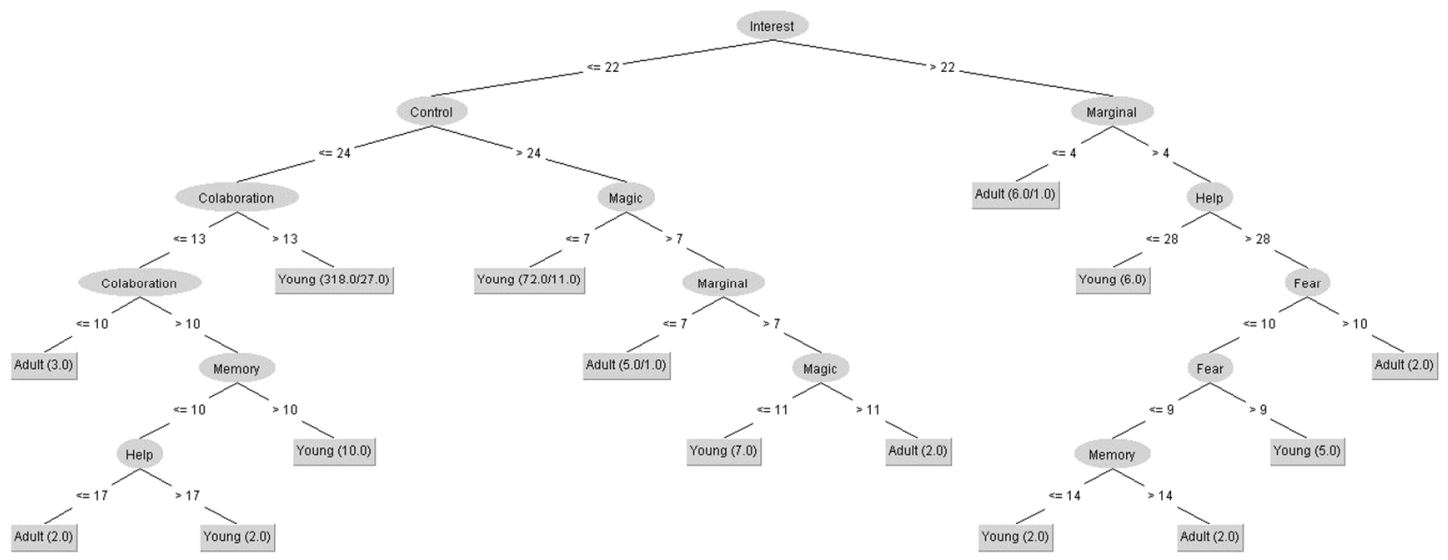

Figure 2. Relationship between scale factors and age of participants at time 2 . 


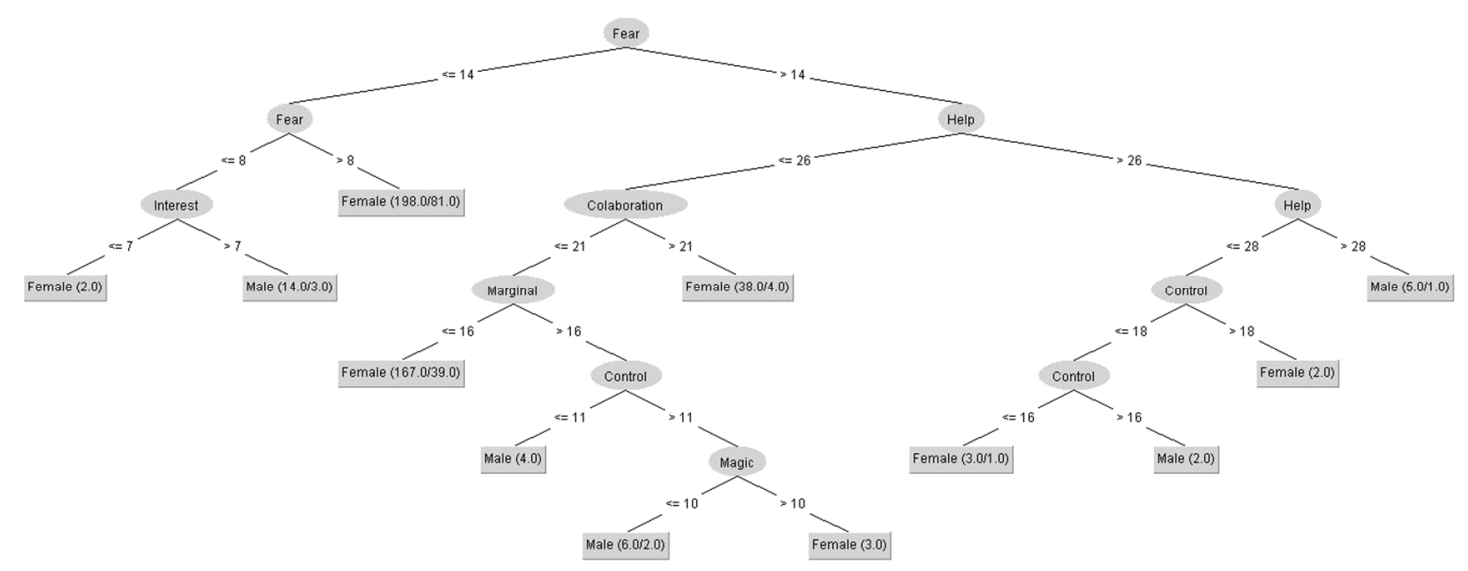

Figure 3. Relationship between scale factors and gender of participants at time 1.

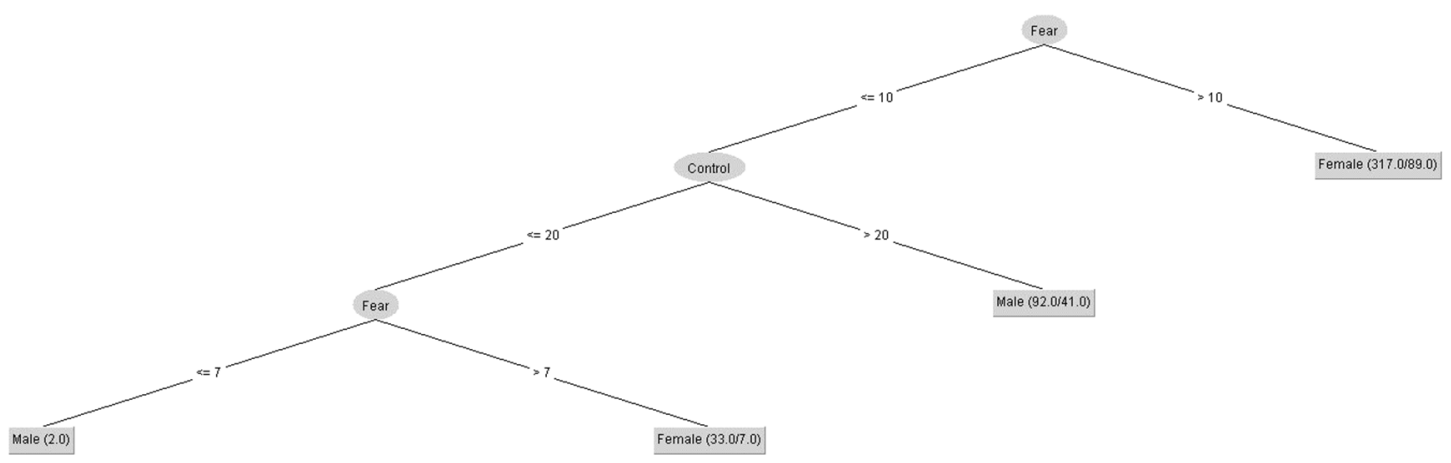

Figure 4. Relationship between scale factors and gender of participants at time 2.

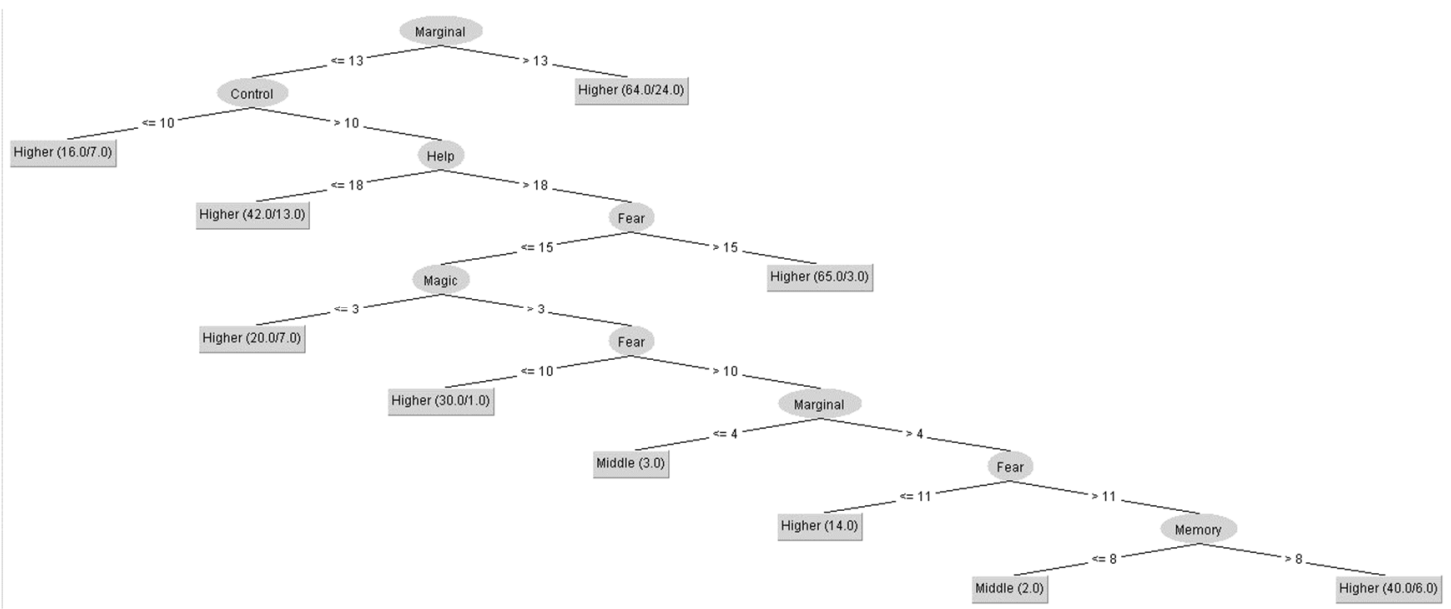

Figure 5. Relationship between scale factors and participants' education level at time 1. 


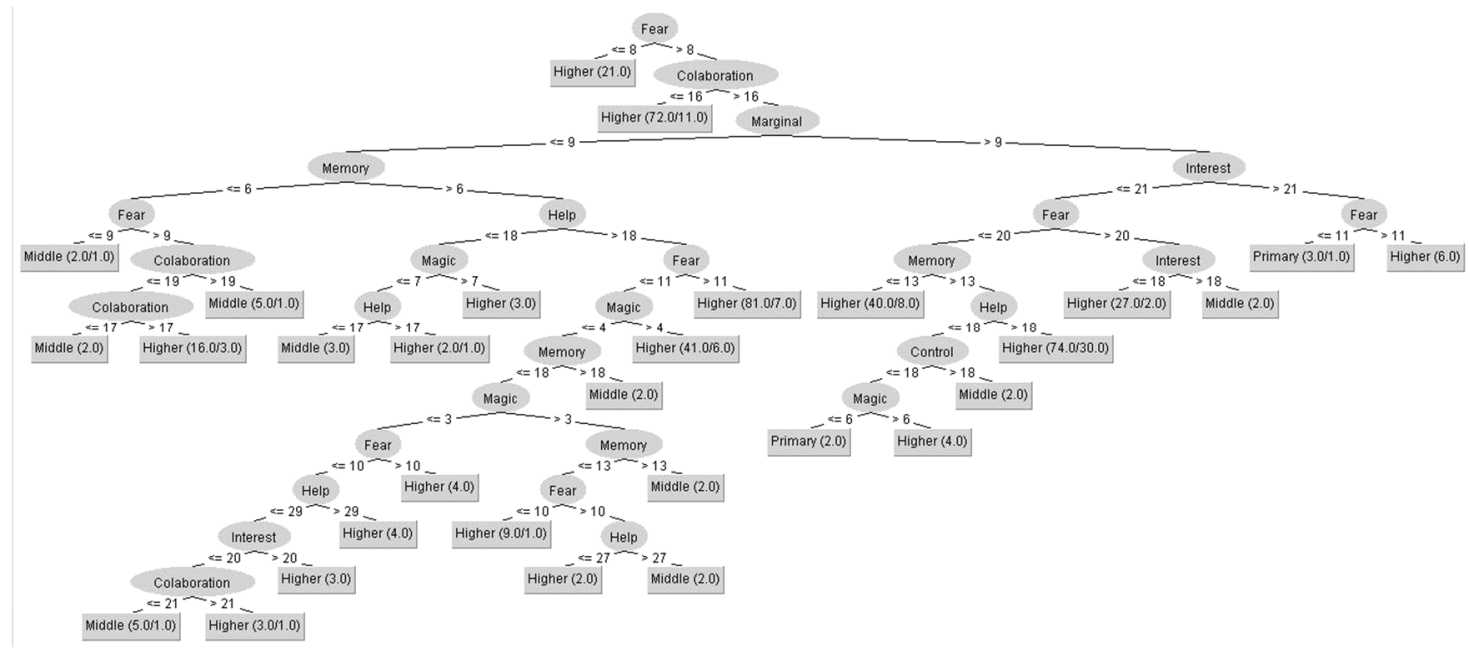

Figure 6. Relationship between scale factors and participants' education level at time 2.

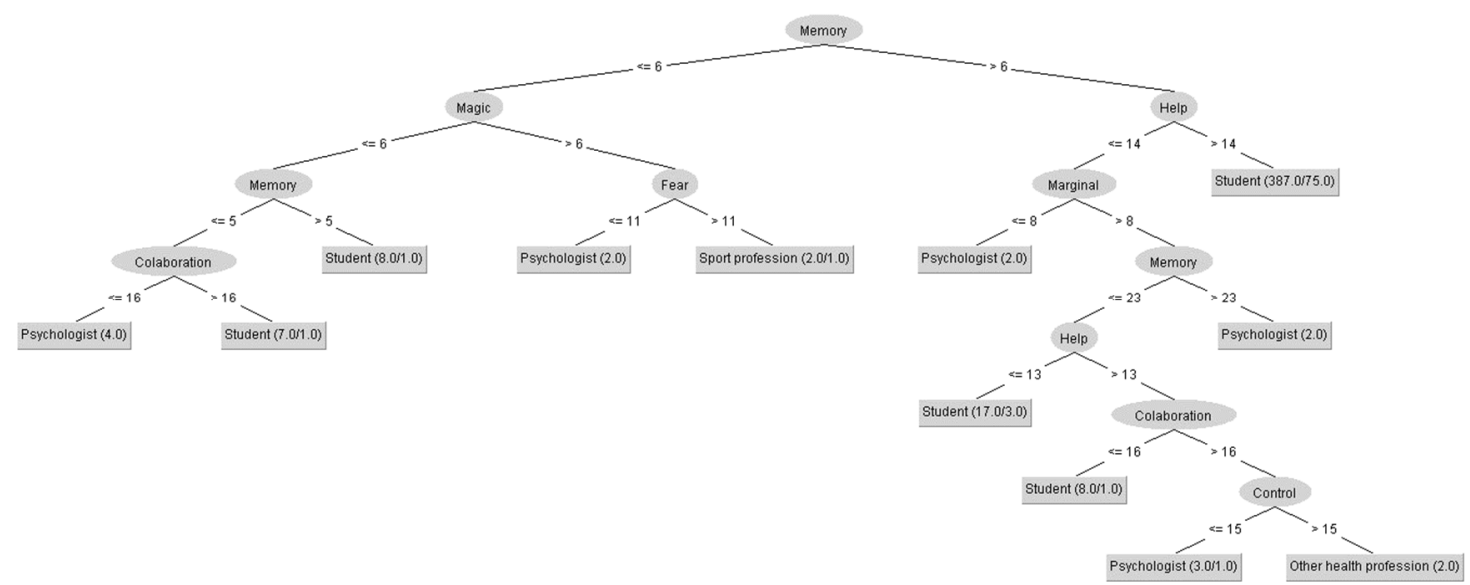

Figure 7. Relationship between scale factors and the profession of the participants at time 1 .

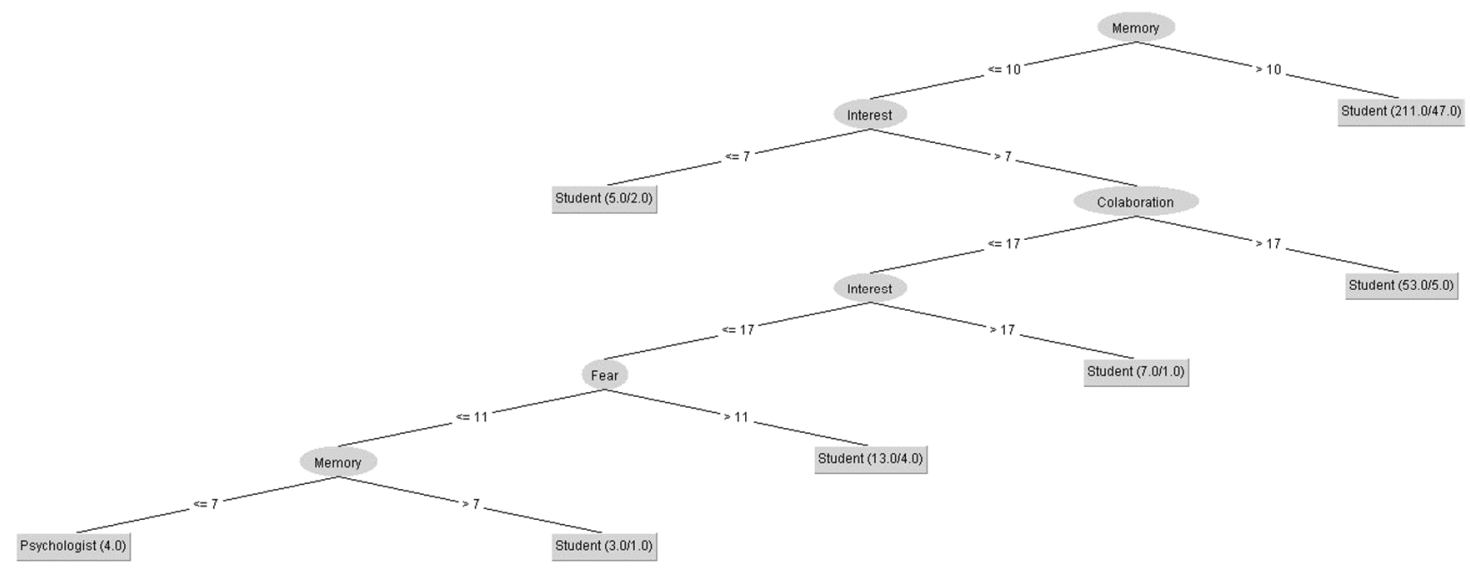

Figure 8. Relationship between scale factors and the profession of the participants at time 2 .

Figures 1 and 2 show the age influence on VSABTH-C factors. In the tree shown in Figure 1, the percentage of correctly classified instances is $85.81 \%$, and in the tree shown in Figure 2, it is $86.04 \%$. Both attempts, 1 and 2, show that age did not have a decisive influence on the score obtained by the participants, because young people and adults scored indistinctly on the factors. 
Figures 3 and 4 show the gender influence on scale factor scores, where the percentage of correctly classified instances was $56.08 \%$ for the first tree and $67.57 \%$ for the second. Both trees (attempt 1 and attempt 2) seem to indicate that in this case, gender had some influence on the scale scores, because women tended to score higher on Control and Fear than men.

Figures 5 and 6 show the influence of the education level on the VSABTH-C factor scores. The percentage of correctly classified instances is $77.25 \%$ in the Figure 5 tree and $73.20 \%$ in the Figure 6 tree. In this case, and according to the results obtained, it can be stated that the education level influenced beliefs and attitudes about hypnosis starting from the middle level (because practically, no relationship was obtained for primary education level participants). More specifically, there seemed to be a tendency among people with a higher education level to score higher on the scales that denote a positive attitude towards hypnosis and lower on those referring to a more negative attitude in both attempts (time 1 and time 2).

Finally, Figures 7 and 8 show the influence of the participants' profession on the factor scores. The percentage of correctly classified instances was $77.25 \%$ for the first time and $77.48 \%$ for the second time. According to the results obtained, the current vocation or profession influenced the factor scores at both time points. The trees showed some relationships for students, psychologists, and other health or sports professions, but excluded people from other professions (e.g., teachers), as well as the unemployed. In addition, at time point 1, psychologists tended to show higher scores than students on factors denoting positive attitudes or beliefs, as well as lower scores than students on those related to negative attitudes or beliefs. However, at time point 2, students slightly changed their opinions regarding factors relating to positive beliefs or attitudes.

\section{Discussion}

The main goal of this study was to analyze information related to beliefs and attitudes regarding hypnosis in a group of participants (client role), using as a tool the decision trees built by WEKA (which allowed us to build a model based on the data set provided and to predict the future behavior of the participants), with the intention of finding out if a set of sociodemographic factors had any kind of influence on these variables.

The decision trees indicated, according to the results obtained, that age did not have a decisive influence on the attitudes and beliefs regarding hypnosis of the participants, since both young people and adults scored indistinctly on the factors of the scale at both times. However, looking at gender, education level, and profession, a certain influence could be observed in the scores obtained in the VSABTH-C factors. Thus, it was observed that women tended to score higher than men in the Control and Fear factors, at both time points. Second, considering the educational level, it was shown that among people with a higher education level, there was a tendency to show more positive attitudes and beliefs about hypnosis than among people with lower education level in both moments. Finally, regarding profession, some relationships were obtained between the scores for the factors and vocation, mainly for students and psychologists, as well as, to a lesser extent, among other health or sports professionals. As such, there was a tendency for psychologists to show more positive attitudes and beliefs towards hypnosis than students at time 1, but students showed a change at time 2 . The percentage of correctly classified instances was, in all cases, higher than $60 \%$, except for the tree where the influence of gender was studied, with $56 \%$ of correctly classified instances, which indicates generally low levels of error.

Therefore, based on the results obtained, it can be concluded that, as a general rule, people with a higher educational level, as well as health professionals (psychologists and others) and students (but not at the first time), show a better predisposition to work with hypnosis; derived from a more positive attitude and more appropriate beliefs about what can be expected from an intervention program with hypnosis. According to these results, the importance of developing and implementing specific training courses in hypnosis, aimed at students or professionals in the field of health is highlighted, since training can 
modify and positively influence the attitudes and beliefs that people show towards this technique, which has been proven to be effective based on a large amount of evidence and has a long scientific background. Finally, considering the results obtained related to gender, it could be interesting to analyze the causes and implications of these results (in terms of what gender implies and how the construction of the sexual role determines the attitude or the behavior of individuals) and whether these results could be replicated in another sample, because the results obtained in previous literature studies are conflicting. In some cases, it was found that women obtain higher scores in factors such as Control or Fear [38], as well as differences in suggestibility [39]; but in other cases no clear differences were found.

Regarding the limitations of the study, it is worth noting the low equity of the sample in terms of sociodemographic variables. Having a more balanced sample, in terms of studies or profession, would have allowed more consistent results owing to the less represented values in the participants, such as age relationships, which did not seem to have any influence in our study.

Nevertheless, and despite the limitation mentioned above, consistent results were obtained that indicate the influence of different sociodemographic variables on attitudes and beliefs towards hypnosis. Therefore, this fact could be used to implement changes or improvements in all those variables where that relationship was found, implementing training courses, as commented before. This would allow, on the one hand, adapting the beliefs and attitudes of the people who were taking that training, as well as providing them with correct information that allows them modify these beliefs and attitudes in other people, and thus turning them into adequate and positive ones.

Based on the above information, future work could aim to produce similar studies with a more heterogeneous sample, as well as including a larger number of variables, which could lead to implementing changes in those whose influence on beliefs and attitudes has been demonstrated. All of this could be done in order to develop intervention programs with safe and effective hypnosis and provide people with adequate information.

Author Contributions: M.A.F., J.L.P.-B., R.E.R., J.P.M.-B., J.A.V.-D., A.H.-M., and V.M.-S. participated in the study design and data collection, performed statistical analyses, contributed to the interpretation of the results, wrote the manuscript, approved the final manuscript as presented, and reviewed and provided feedback to the manuscript. A.H.-M., J.L.P.-B., and M.A.F. conceived the study and participated in its design and coordination. All authors made substantial contributions to the final manuscript. All authors have read and agreed to the published version of the manuscript.

Funding: This research received no external funding.

Institutional Review Board Statement: The work was approved by the Ethics Committee of the University of Malaga No. 19-2015-H. In addition, the guidelines of the Declaration of Helsinki (revision of 2013), the recommendations of Good Clinical Practice of the EEC (document 111/3976/88 of July 1990) and the current Spanish legal regulations governing clinical research in humans (Royal Decree 561/1993) were followed.

Informed Consent Statement: The Informed Consent appears in the Conditions accepted when registering on the platform MenPas, which are made in accordance with the provisions of Law 15/1999 of 13 December on the Protection of Personal Data (LOPD), the user registered on the platform authorizes that the data provided will be incorporated and processed in the electronic file owned MenPas.

Data Availability Statement: Not applicable.

Conflicts of Interest: The authors declare no conflict of interest. 


\section{References}

1. Pastrana, J.L.; Reigal, R.E.; Morales-Sánchez, V.; Morillo-Baro, J.P.; de Mier, R.J.-R.; Alves, J.; Hernández-Mendo, A. Data Mining in the Mixed Methods: Application to the study of the psychological profiles of athletes. Front. Psychol. 2019, 10, 2675. [CrossRef] [PubMed]

2. Kaur, G.; Chhabra, A. Improved J48 classification algorithm for the prediction of diabetes. Int. J. Comput. Appl. 2014, 98, 13-17. [CrossRef]

3. Koh, C.H.; Tan, G. Data Mining applications in Healthcare. J. Healthc. Inf. Manag. 2005, 19, 64-72.

4. Moret-Tatay, C.; Baixauli-Fortea, I.; Grau Sevilla, M.D.; Irigaray, T.Q. Can you identify these celebrities? A network analysis on differences between word and face recognition. Mathematics 2020, 8, 699. [CrossRef]

5. Zhang, C.; Jiang, J.; Jin, H.; Chen, T. The Impact of COVID-19 on Consumers' Psychological Behavior Based on Data Mining for Online User Commets in the Catering Industry in China. Int. J. Environ. Res. Public Health 2021, 18, 4178. [CrossRef] [PubMed]

6. Ying, Y.; Kaku, I.; Tang, J.; Zhu, J. Data Mining. Concepts, Methods and Applications in Management and Engineering Design; Springer: London, UK, 2011.

7. Zaki, M.J.; Meira, W., Jr. Data Mining and Analysis: Fundamental Concepts and Algorithms; Cambridge University Press: Cambridge, UK, 2014. [CrossRef]

8. Witten, I.H.; Frank, E.; Hall, M.A.; Pal, C.J. Data Mining: Practical Machine Learning Tools and Techniques; Morgan Kaufmann: San Francisco, CA, USA, 2016.

9. Dutt, A.; Aghabozrgi, S.; Ismail, M.A.B.; Mahroeian, H. Clustering algorithms applied in educational data mining. Int. J. Inf. Electron. Eng. 2015, 5, 112-116. [CrossRef]

10. Thomas, M.C.; Zhu, W.; Romagnoli, J.A. Data mining and clustering in chemical process databases for monitoring and knowledge discovery. J. Process Control 2018, 67, 160-175. [CrossRef]

11. Korting, T.S. C4.5 Algorithm and Multivariate Decisión Tres. 2006. Available online: https://docs.google.com/viewer?a=v\&pid= sites\&srcid=d2F2ZWJvcm4uY29tfHdhdmVib3JuLXdpa218Z3g6YWY4ZmE5NDNkZGE5N2Fk (accessed on 9 July 2021).

12. Navas-Moreno, F. Introducción a la Minería de Datos con WEKA: Aplicación a un Problema Económico (Trabajo Fin de Grado); Universidad de Jaén: Jaén, España, 2016.

13. Fayyad, U.M. Advances in knowledge discovery: Making sense out of data. IEEE Expert 1996, 11, 20-25. [CrossRef]

14. Otero, J.; Sánchez, L. Induction of descriptive fuzzy classifiers with the logitboost Algorithm. Soft Comput. 2006, 10, 825-835. [CrossRef]

15. Moertini, V.S. Towards the use Of C4.5 Algorithm for classifying banking dataset. Integral 2003, 8, 105-116.

16. Bhargava, N.; Sharma, G.; Bhargava, R.; Mathuria, M. Decision tree análisis on J48 algorithm for data mining. Int. J. Adv. Res. Comput. Sci. Softw. Eng. 2013, 3, 1114-1119.

17. Quinlan, J.R. Induction of decisión trees. Mach. Learn. 1986, 1, 81-106. [CrossRef]

18. Capafons, A.; Morales, C.; Espejo, B.; Cabañas, S. Análisis factorial exploratorio y propiedades psicométricas de la escala de Valencia de actitudes y creencias hacia la hipnosis, versión terapeuta. Psicothema 2006, 18, 810-815.

19. Capafons, A. Hipnosis: Segunda Edición Ampliada y Revisada; Sintesis: Madrid, Spain, 2012.

20. Capafons, A.; Lamas, J.R.; Lopes-Pires, C. Hipnosis: Técnicas de Modificación de Conducta; Labrador Encinas, F.J., Ed.; Pirámide: Madrid, Spain, 2008; pp. 593-614.

21. Spanos, N.P.; Brett, P.J.; Menary, E.P.; Cross, W.P. A measure of attitudes toward hypnosis: Relationships with absorption and hypnotic susceptibility. Am. J. Clin. Hypn. 1987, 30, 139-150. [CrossRef]

22. Barber, T.X. Hypnosis: A scientific Approach; Van Nostrand Reinchold: New York, NY, USA, 1969.

23. Lynn, S.J.; Kirsch, I. Essentials of Clinical Hypnosis: An Evidenced Based Approach; American Psychological Association: Washington, DC, USA, 2006.

24. Spanos, N.P.; Chaves, J.F. Hypnosis: The Cognitive-Behavioral Perspective; Prometheus Books: Amherst, NY, USA, 1989.

25. Mendoza, M.E.; Capafons, A.; Jensen, M.P. Hypnosis attitudes: Treatment effects and associations with symptoms in individuals with cancer. Am. J. Clin. Hypn. 2017, 60, 50-67. [CrossRef] [PubMed]

26. Schoenberger, N.E.; Kirsch, I.; Gearan, P.; Montgomery, G.; Pastyrnak, S.L. Hypnotic enhancement of a cognitive behavioral treatment for public speaking anxiety. Behav. Ther. 1997, 28, 127-140. [CrossRef]

27. Capafons, A.; Alarcón, A.; Cabañas, S.; Espejo, B. Análisis factorial exploratorio y propiedades psicométricas del cuestionario de creencias y actitudes hacia la hipnosis-cliente. Psicothema 2003, 15, 143-147.

28. Capafons, A.; Suárez-Rodríguez, J.M.; Selma, M.L. Análisis factorial confirmatorio de la escala valencia de actitudes y creencias hacia la hipnosis (versión cliente revisada) en una muestra española. An. Psicol. 2015, 31, 84-95. [CrossRef]

29. Alarcón, A.; Capafons, A. El modelo de Valencia de hipnosis despierta: ¿técnicas nuevas o técnicas innovadoras? Pap. Psicolog. 2006, 27, 70-78.

30. Capafons, A. La hipnosis despierta setenta y cuatro años después. An. Psicol. 1999, 15, 77-78.

31. Capafons, A.; Mendoza, E. Waking hypnosis in clínical practice. In Handbook of Clinical Hypnosis, 2nd ed.; Labrador Encinas, S.J., Rhue, J.W., Kirsch, I., Eds.; American Psychological Association: Washington, DC, USA, 2010; pp. 293-317. [CrossRef]

32. Green, J.P.; Houts, C.R.; Capafons, A. Attitudes about hypnosis Factor analyzing the VSABTH-C with an American sample. Am. J. Clin. Hypn. 2012, 54, 167-178. [CrossRef] [PubMed] 
33. Capafons, A.; Cabañas, S.; Espejo, B.; Cardeña, E. Confirmatory factor analysis of the Valencia scale on attitudes and beliefs toward hypnosis: An international study. Int. J. Clin. Exp. Hypn. 2004, 52, 413-433. [CrossRef]

34. González-Ruíz, S.L.; Domínguez-Alfonso, R.; Chica-Merino, E.; Pastrana-Brincones, J.L.; Hernández-Mendo, A. Una plataforma virtual para la evaluación e investigación on-line: Menpas. Cuad. Psicol. Deport. 2018, 18, 26-48. [CrossRef]

35. González-Ruíz, S.L.; Hernández-Mendo, A.; Pastrana-Brincones, J.L. Herramienta software para la evaluación psicosocial de deportistas y entornos deportivos. Lect. EF Deportes. Rev. Digit. 2010, 15. Available online: http://www.efdeportes.com/efd144 / evaluacion-psicosocial-de-deportistas.htm (accessed on 17 September 2019). [CrossRef]

36. World Medical Association. World Medical Association Declaration of Helsinki: Ethical principles for medical research involving human subjects. J. Am. Med. Assoc. 2013, 310, 2191-2194. [CrossRef] [PubMed]

37. King, M.W.; Resick, P.A. Data Mining in psychological treatment research: A primer on classification and regression trees. J. Consult. Clin. Psychol. 2014, 82, 895-905. [CrossRef] [PubMed]

38. González-Pérez, A. Escala de Valencia de Actitudes y Creencias Hacia la Hipnosis: Una Aproximación a la Modelización de las Relaciones Complejas Entre las Dimensiones de las Actitudes Hacia la Hipnosis (Tesis doctoral); Universitat de València: Valencia, España, 2018.

39. González-Ordi, H.; Miguel-Tobal, J.J. Características de la sugestionabilidad y su relación con otras variables psicológicas. An. Psicol. 1999, 15, 57-75. 